\title{
Experimental Determination of Residual and Remaining Oil in Laminated Rock Samples
}

\author{
Huang Y., Ringrose P. S., Sorbie K. S. \\ Heriot Watt University, \\ Dept. Petroleum Engineering, U. K.
}

\begin{abstract}
Copyright 1995, Steering Committee of the European IOR - Symposium.
This paper was presented at the 8th. European IOR - Symposium in Vienna, Austria, May 16 - 17, 1995

This paper was selected for presentation by the Steering Committee, following review of information contained in an abstract

submitted by the author(s). The paper, as presented has not been reviewed by the Steering Committee.
\end{abstract}

\begin{abstract}
We have performed a series of water-oil drainage and imbibition floods on laminated slabs of aeolian rock, using CT imaging techniques to monitor the saturation evolution. Experiments with flow both parallel to and perpendicular to lamination have been conducted, and the role of viscous and capillary forces has been assessed by flooding at different rates.

For capillary-dominated conditions (at typical interwell waterflood flow rates), the remaining oil saturation is around $40-50 \%$ of original oil in place. For flow across laminae, the interaction of capillary forces with the lamination causes rapid water imbibition into lower permeability layers, resulting in oil trapping in the higher permeability layers (up to 55\%). For flow along laminae, capillary trapping is reduced but flow bypassing results in similar levels of oil retention. For viscousdominated (high flow rate) experiments, the oil recovery is generally higher due to the suppression of capillary forces, although bypassing can occur. Locally (within laminae) the residual oil saturation is a strong function of permeability (in the range of $10 \%$ to $50 \%$ ). However, the interaction of the heterogeneity with multiphase flow dynamics means that the remaining oil (at the formation scale) is usually much higher than the average (pore-scale) residual oil.
\end{abstract}

These results have great significance for petrophysical and reservoir engineering studies. It is clear that residual oil determinations from uniform core plug samples do not necessarily represent the oil retention that occurs at the reservoir formation scale. Furthermore, the presumed residual oil saturation after waterflood may be much higher than indicated from traditional core analysis.

\section{Introduction}

Before applying any improved oil recovery (IOR) process, it is essential to establish the amount and nature of the remaining oil which forms the 'target' for that process. In essence each IOR process changes one or more of the force balances (viscous/capillary; viscous/ gravity) in order to release, or increase the recovery rate of, this remaining oil. In laminated sandstones, there are interactions between the capillary forces and the rock structure which lead to oil trapping mechanisms at the lamina scale. The extent and nature of this type of trapping depends on the permeability contrast between laminae, the details of the laminaset structure (planar lamination, ripple-lamination, crosslamination, etc.), the system wettability and the balance of forces in the displacement 
process 1,2 . Clearly, the design criteria for any IOR method will be affected by the details of such oil trapping mechanisms, and the property requirements may be rather different from the case where the target oil is trapped only at the pore scale.

The sedimentary structure of clastic rocks at the laminaset scale can thus have an important influence on the amount and nature of "remaining oil" after a waterflood. This has been found in previous experimental, numerical simulation and theoretical work from our group ${ }^{1-6}$ as well as by other groups. ${ }^{7-}$ 13 Oil trapping, due to the interaction of capillary forces with small-scale reservoir heterogeneity is important for at least in three aspects of reservoir engineering:

1. Determination of Remaining Oil: Capillaryheterogeneity trapping represents a scale and type of oil retention which is intermediate between pore-scale oil retention (usually referred to as residual oil) and reservoir-scale bypassing of oil (usually referred to in terms of macroscopic sweep efficiency). We call this intermediate scale of oil retention "Lamina-trapping" and refer to the corresponding oil volume as "remaining oil" in order to differentiate it from pore-scale residual oil.

2. Core analysis: Experiments aimed at measuring the "residual oil" and connate water saturations, and corresponding relative permeability functions, may frequently encapsulate the capillary-heterogeneity effect in the measurement, so that what is measured as "residual oil" is actually the "remaining oil" at the core-scale for an arbitrarily selected and orientated piece of the reservoir.

3. Upscaling: A clear differentiation of porescale, lamina-scale and field-scale oil retention is essential to proper reservoir engineering, and must be captured in reservoir simulation models by a consistent upscaling method ${ }^{1,2,9}$.

In this paper, results are presented from a series of water-oil, drainage and imbibition floods in laminated slabs of rock. These carefully-monitored floods were designed to establish the nature of remaining oil at the small scale. CT imaging techniques were used to accurately record the saturation evolution in the heterogeneous media. Experiments with flow parallel and perpendicular to lamination have been conducted, and the role of viscous and capillary forces have been assessed by flooding at different rates. The displacement of oil along the laminated structure of clastic sediments is significantly different from crosslamina displacements. The lamina trapping of oil in such displacements is thought to depend on a number of factors such as viscous/capillary ratio, the magnitude of the laminae permeability contrast and the wettability of the fluid/rock system. These results highlight the fact that the small scale sedimentary structure may be important in determining "remaining oil". Our findings also have important consequences for how core scale petrophysical measurements are made. The same displacement physics has an important bearing on two phase flow anisotropy and scaleup of two phase flow.

\section{Experimental Procedure}

Rock and Fluid Properties: The sandstone used for the experiments is an aeolian New Red Sandstone from Lochabriggs, in the south of Scotland. The rock slabs used (Figure 1) have dimensions of $20 \mathrm{~cm}$ by $10 \mathrm{~cm}$ by $1 \mathrm{~cm}$. The permeabilities of the laminations in the slabs varied from 30 to $6000 \mathrm{mD}$, and displayed a fairly regular alternation of high and low permeability laminae.

\begin{tabular}{|l|l|l|l|}
\hline $\begin{array}{l}\text { Experiment } \\
\text { Rock Slab }\end{array}$ & C3C & P5B & P5C \\
\hline $\begin{array}{l}\text { Laminae } \\
\text { orientation }\end{array}$ & $\begin{array}{l}\text { Normal to } \\
\text { long axis }\end{array}$ & $\begin{array}{l}\text { Parallel to } \\
\text { long axis }\end{array}$ & $\begin{array}{l}\text { Parallel to } \\
\text { long axis }\end{array}$ \\
\hline Pore Volume & $42 \mathrm{~cm}^{3}$ & $46 \mathrm{~cm}^{3}$ & $46 \mathrm{~cm}^{3}$ \\
\hline Porosity & 0.216 & 0.210 & 0.210 \\
\hline $\begin{array}{l}\text { Postflush } \\
\text { direction }\end{array}$ & $\begin{array}{l}\text { across } \\
\text { laminae }\end{array}$ & $\begin{array}{l}\text { along } \\
\text { laminae }\end{array}$ & $\begin{array}{l}\text { lalong } \\
\text { laminae }\end{array}$ \\
\hline Flow rate & $1 \mathrm{ml} / \mathrm{h}$ & $5 \mathrm{ml} / \mathrm{h}$ & $450 \mathrm{~m} / \mathrm{h}$ \\
\hline
\end{tabular}

Table 1. Summary of experimental rock slabs and flooding experiments

The fluids used were decane oil, (having a density of $0.74 \mathrm{~g} / \mathrm{cm}^{3}$ and a viscosity of 0.90 $\mathrm{cp}$ at $\left.21^{\circ} \mathrm{C}\right)$ and $\mathrm{NaI}(200 \mathrm{~g} / \mathrm{l})$ doped brine (prepared using degassed distilled water having a density of $1.14 \mathrm{~g} / \mathrm{cm}^{3}$ and a viscosity of $1.03 \mathrm{cp}$ at $21^{\circ} \mathrm{C}$ ), the main features of each experiment are summarised in Table 1.

\section{Flooding Procedure - Oil-drainage:} Achieving an appropriate and reproducible initial fluid saturation is very important for the success of the experimental work. To establish the initial oil and water saturations, a gravity-stable drainage flood was carried out with decane displacing water from a $100 \%$ brine-saturated slab. After initial imbibition of doped brine into the dry slab, the slab was kept in a vertical orientation and decane oil was injected across laminations from the top 
inlet at a very low flow rate $(1 \mathrm{ml} / \mathrm{h})$ until a maximum oil saturation was reached. It is demonstrated in the results that the initial oil saturations could be repeatedly reproduced very accurately in this way.

Flooding Procedure - Water-imbibition postflush: Floods with flow across (C3B) or along (P5B and P5C) the laminations were conducted with the slab lying horizontally to minimise the effects of gravity. The whole flooding procedure is similar to that reported in a previous paper ${ }^{3}$. One major improvement in this work is that, during the doped brine postflush of experiment P5B, the whole displacement was tracked by carrying out repeated CT scans, so that the detailed flooding history was recorded.

The flow direction and rate used in the brine imbibition postflush are indicated in Table 1. The average porosity, $\bar{\phi}$, average fluid saturations, $S_{w i}, S_{\text {or }}$, as well as the total oil recovery were calculated both by weighing and by material balance, in addition to estimation from the imaging work. These independent measures agreed very well.

CT imaging: X-ray CT images were acquired using a fourth-generation Siemens CT scanner - the Somatom-plus - at the Western General Hospital, Edinburgh. A 2D topogram imaging technique was used in this work for a number of reasons which have been outlined previously ${ }^{3}$ A comprehensive method has been developed to calibrate the original image data and to minimise the effects of beam hardening and image processing. Details of the $\mathrm{CT}$ resolution and image manipulation are given elsewhere ${ }^{3,4}$ Each image profile shown here involves a $1 \mathrm{~cm}$ (11 point) running average along lines of across laminations, and these have been averaged over the entire length along the laminations.

\section{Results}

Calibration of Porosity and Permeability: The permeability distribution of the slabs was measured initially using an automated probe permeameter (PDPK-200) prior to setting it in a resin cast. The average porosity was determined by fluid material balance and tracer analysis in (Table 1). Permeability and porosity were then estimated from the image data. The CT-based estimates of $k$ and $\phi$ assume the following:

(a) permeability is proportional to the inverse of rock density (i.e. the rock+air image) and

(b) effective brine-filled porosity is a function of the difference between the rock+air and rock+brine images.

Note that the CT-derived permeability estimate is independent of the probe measurements. Comparisons of the CT permeability and porosity profile with the probe permeability profile, along the width of slab P5, were made and are shown in Figure 2. Significant variations both in porosity and in permeability can be seen, and the porosity and (logarithmic) permeability profiles are very closely correlated. Similar results were also obtained for slab C3.

Figure 3 shows the CT- and probe-derived permeability values as a function of CTporosity for rockslabs C3 and P5, and indicates the following:

- There is a good correlation between log permeability (CT-based or probe-based) and porosity.

- A permeability variation of around 100:1 for slab P5 is observed which is much higher than shown in slab C3 (around 10:1). Similar results can be found for the porosity variation.

- In spite of the different variation of $k$ and $\phi$ between slab C3 and P5, the $k-\phi$ relationship for both slabs are very similar.

It will be shown that the good $\mathrm{k} / \phi$ correlation and the consistency between CT and probe estimates of permeability provide a good basis for estimation of capillary pressure effects in numerical simulations.

Capillary-dominated cross-lamina flow $(C 3 B)$ : Figure 4 shows the distribution of remaining oil saturation, $S_{\text {or }}$, along the slab length at the end of the imbibition flood C3B (the flow direction is from left to right across the laminae). The observed $S_{\text {or }}$ distribution indicates the following features:

- In the regions corresponding to low permeability layers (e.g. at $B$ and D), $S_{\text {or }}$ is quite low at around $15 \%$, compared with the average level of about $35 \%$.

- High $S_{o r}$ is observed in the central region and upstream end of the slab (at $A$ and $C$ ), where it ranges from $30 \%$ up to $55 \%$. These high $S_{\text {or }}$ zones lie in high permeability layers upstream of low permeability laminae.

- The first of these high $S_{\text {or }}$ regions (A) is trapped behind a very thin $(2 \mathrm{~mm})$, low- 
k, iron-stained lamina characterised by pressure solution and hematite coatings on grains. ${ }^{3}$

- There is a general trend of decreasing $S_{\text {or }}$ towards the outlet end of the slab.

The characteristics of the distribution of remaining oil in cross-lamina flow are in close accord with our detailed understanding of the rock fabric ${ }^{3}$. We anticipated rapid imbibition of the low permeability layers to result in oil trapping upstream of these low permeability layers. This is clearly observed upstream of the $1 \mathrm{~cm}$-thick low permeability region at $D$, which was detected by probe permeametry. It is also evident upstream of the thin, low permeability, iron-stained layer at B, which was only identified in detail in the thin section analysis. ${ }^{3}$

Figure 5 shows the oil recovery (\%OOIP) distribution along the slab length. This graph shows the following interesting features:

- high oil recovery efficiency (50-65\%) is found in higher permeability regions just downstream the low permeability layers;

- low oil recovery (10-20\%) occurs in the upstream high-permeability regions adjacent to those low-k layers;

- within the low permeability layers the oil recovery efficiency is variable but fairly low.

Thus, in the low flow rate cross-lamina case, we observed high remaining oil in high permeability layers upstream of low permeability layers. These findings corroborate our earlier predictions that significant capillary trapping occurs in crosslaminated systems. 1,2 .

We were unable to perform a high flow rate (viscous dominated) flood of slab $\mathrm{C} 3$ because of its low effective permeability and the pressure limitations of our apparatus.

Capillary-dominated, along-lamina flow $(P 5 B)$ : In this case we imaged the saturations at several stages of the imbibition cycle, as shown in Figure 6 . The permeability distribution for this slab is shown in Figure 2. The $S_{\text {or }}$ distributions at different stages of water injection (Figure 6) show several interesting features.

- In the high permeability layers the oil saturation decreases significantly and at a uniform rate as water is injected;up to about 0.25 PV.

- The final remaining oil saturation, $S_{o r}$, varies from less $1 \%$ to over $60 \%$, and depends on the initial oil saturation, $S_{\mathrm{oi}}$, and the permeability: Generally, high $S_{\text {or }}$ occurs in high $\mathrm{k}$ layers and low $S_{\text {or }}$ in low $\mathrm{k}$ layers;

- By about one quarter of a pore volume (PV) of water injection, the remaining oil saturation is very close to the final $S_{\text {or. }}$.

The last two points imply that a lot of water injected has bypassed the high $k$ layers, probably by flow along the low $\mathrm{k}$ layers. It is possible that at the low flow rate $(5 \mathrm{ml} / \mathrm{h}$ or $0.56 \mathrm{~m} /$ day) and very low initial oil saturation (about $10 \%$ ), resulted in rapid water imbibition and breakthrough through one particular low $\mathrm{k}$ layer. This may explain the high oil retention in the high $\mathrm{k}$ layers, despite the along-layer flow arrangement.

This suggestion is supported by the plot of oil recovery distributions along the slab width, shown in Figure 7. Note that:

- The highest oil recovery efficiency (\%OOIP) occurs in the lowest-k layer at the very beginning of water postflush, which implies that early imbibition is occurring in the lowest-k layer;

- Oil recovery in the high-k regions increases relatively uniformly, and the final \%OOIP is about $40-50 \%$ in these regions;

- The final \%OOIP in the low-k regions is very variable and generally low with the notable exception of highest \%OOIP observed in the lowest-k layer. However, we note that there was initially very little oil in these low permeability laminae.

Because of the large variation in initial oil saturation in different layers, it is difficult to gain a clear impression of the real oil recovery distribution from Figure 7 . For this reason, a new parameter, oil recovery index (ORI), is defined as the ratio of localised oil produced to average oil produced. The estimate of ORI in each pixel is given by:

$$
(O R I)_{j}=\frac{N\left[\left(S_{o i}\right)_{j}-\left(S_{o r}\right)_{j}\right]}{\sum_{i=1}^{N}\left[\left(S_{o i}\right)_{i}-\left(S_{o r}\right)_{i}\right]}
$$

where $\mathrm{j}$ is the individual pixel number and $\mathrm{N}$ is the total pixel number. Figure 8 shows the ORI distribution alongside the corresponding permeability distribution. The two curves correlate well. Generally the high-k regions give the highest relative amount of oil recovery and the low-k regions show much lower oil recovery. 
Viscous-dominated along-lamina flow (P5C): For this work, the slab P5, was carefully resaturated with decane in order to facilitate comparison with the previous experiment (P5B). A closely matching initial water saturation distribution, $S_{w i}$, was obtained as shown in Figure 9. Clearly, the initial oil saturation in this heterogeneous rock is far from uniform and strongly depends on the permeability and porosity variation in the porous medium (cf. Figure 2). There are distinct regions of high $\mathrm{S}_{w i}$, up to about $90 \%$, corresponding to a low-k layer and of low $S_{w i}$, down to below $10 \%$, corresponding to highest$\mathrm{k}$ layers.

The brine imbibition postflush in this case was performed at a high flow rate, $450 \mathrm{ml} / \mathrm{h}$ or about $51 \mathrm{~m} / \mathrm{day}$, which gives a viscousdominated flow. We observed a higher oil recovery in some high $\mathbf{k}$ regions in this experiment. The difference in the two experiments are illustrated by a plot of the change in oil recovery defined by:

$$
\frac{(\mathrm{OR})_{\mathrm{P} 5 \mathrm{C}}-(\mathrm{OR})_{\mathrm{P} 5 \mathrm{~B}}}{(\mathrm{OR})_{\mathrm{P} 5 \mathrm{~B}}}
$$

This is shown in Figure 10. Interestingly, all the high $\mathrm{k}$ regions show an increased in oil recovery. Conversely, decreased oil recovery is observed in certain low $k$ layers. The similarities and differences in oil recovery between the viscous-dominated flow (P5C) and the capillary-dominated flow (P5B) can be summarised and interpreted as follows:

i. The general pattern of oil recovery distribution for along lamina flow is similar whether viscous- or capillary-dominated(ie, better recovery from high $k$ layers), and significantly different from across-lamina flow. (ie, oil trapping in high $\mathrm{k}$ layers).

ii. Bypassing of brine through one low $k$ layer by spontaneous imbibition was proposed for the low flow rate case (P5B). However at the higher flow rate (P5C), the water front advances more rapidly in the high $\mathbf{k}$ layers which appears to reduce the degree of brine bypassing in the low-k layers.

iii. The higher recovery in the high $\mathrm{k}$ region for the high rate flood (P5C) may be due to the high pressure gradient displacing oil on the "negative" branch of the capillary pressure curve (i.e. the "forced imbibition" region).

\section{Summary and Conclusions}

The main results for experiments $C 3 C$ (capillary-dominated cross-lamina flow), P5B (capillary-dominated along-lamina flow) and P5C (viscous-dominated along-lamina flow) from laboratory mass balance and from the CT image data are shown in Table 2.

The match between the different material balance and CT scan estimates in each individual case is very consistent, despite the fact that they have been derived independently.

For capillary-dominated conditions (at typical interwell waterflood flow rates) the average remaining oil saturation is around $35-40 \%$ of original oil in place. There is little difference in total $S_{\text {or }}$ between cross-lamina and alonglamina flows from Table 2. However, oil distribution and trapping mechanisms are totally different. For flow across lamina flow, the interaction of capillary forces with the lamination causes rapid water imbibition into lower permeability layers, resulting in capillary-heterogeneity oil trapping (laminatrapping) in the higher permeability layers (up to $55 \%$ ). For flow along lamina, the capillary trapping is reduced but flow bypassing may result in similar levels of oil retention.

For viscous-dominated (high flow rate) experiments, (along-layer flow only), the oil recovery is generally higher due to the suppression of capillary forces, although bypassing does occur. Locally (within laminae) the residual oil saturation is a strong

\begin{tabular}{|l|r|r|r|r|r|r|}
\hline \multirow{2}{*}{ Parameter } & \multicolumn{2}{|c|}{ C3B } & \multicolumn{2}{c|}{ P5B } & \multicolumn{2}{c|}{ P5C } \\
\cline { 2 - 7 } & $\begin{array}{c}\text { Mass } \\
\text { Balance }\end{array}$ & $\begin{array}{c}\text { X-ray } \\
\text { Imaging }\end{array}$ & $\begin{array}{c}\text { Mass } \\
\text { Balance }\end{array}$ & $\begin{array}{c}\text { X-ray } \\
\text { Imaging }\end{array}$ & $\begin{array}{c}\text { Mass } \\
\text { Balance }\end{array}$ & $\begin{array}{c}\text { X-ray } \\
\text { Imaging }\end{array}$ \\
\hline $\begin{array}{l}\text { Initial water } \\
\text { saturation, }\end{array}$ & 0.429 & 0.437 & 0.356 & 0.367 & 0.380 & 0.385 \\
\hline $\begin{array}{l}\text { Remaining oil } \\
\text { saturation, }\end{array}$ & 0.357 & 0.348 & 0.391 & 0.393 & 0.337 & 0.338 \\
\hline $\begin{array}{l}\text { Oil Recovery, } \\
\text { \%OOIR }\end{array}$ & 0.375 & 0.369 & 0.393 & 0.392 & 0.456 & 0.450 \\
\hline
\end{tabular}

Table 2 Summary of results from the three experiments 
function of permeability (in the range of $10 \%$ to $50 \%$ ). However, the interaction of the heterogeneity with multiphase flow dynamics means that the remaining oil (at the formation scale) is usually much higher than the average (pore-scale) residual oil.

We summarise the main conclusions and implications of this work:

1. This experimental work clearly shows the significance of oil trapping within sediment heterogeneity at the lamina scale. This type of experiment is much more informative for understanding reservoir behaviour than the traditional viscousdominated experiments on "uniform" core plug samples.

2. Under capillary-dominated cross-lamina flow conditions, experimental work has confirmed the importance of low permeability layers on the overall flow behaviour and oil trapping properties. Most oil is trapped in the upstream regions of low permeability layers, leaving up to $55 \%$ of remaining oil saturation in these areas.

3. Under capillary-dominated, along-lamina flow conditions most of the remaining oil is in the (or high permeability), regions although the amount of oil produced is much higher from high- $\mathrm{k}$ regions than from low-k regions. The relatively poor oil recovery efficiency from high-k regions is thought to be due to the imbibition of water along one very low-k layers.

4. Higher oil recovery efficiency in the high $\mathrm{k}$ layers is observed in viscous-dominated along-lamina flow compared with the corresponding work in capillary-dominated flow. This is probably due to the reduced bypassing of water along the very low-k layers, and the higher pressures displacing oil in the "forced imbibition" branch of the capillary pressure curve in high $\mathrm{k}$ regions.

5. Considerable care is needed when interpreting capillary-dominated (low flow-rate) two-phase flow experiments, as the details of the small-scale petrophysical properties plays a significant role. Core analysis that does not take account of these core-scale oil trapping effects may lead to serious misinterpretations. In particular the determination of field-wide residual oil saturation from core plug measurements assumed to be 'homogeneous' must be treated with extreme caution. If the nature and amount of this remaining oil is not considered then a potential IOR method may not be appropriately designed.

6. The results observed in this work will also depend on the wettability of the system. We have addressed this in very recent work to be reported in a forthcoming publication.

$\begin{array}{ll}\text { Nomenclature } \\ \mathrm{CT} & \text { computerised tomography } \\ \mathrm{j} & \mathrm{CT} \text { image pixel number } \\ \mathrm{k} & \text { permeability in mD } \\ \text { OR } & \text { oil recovery } \\ \text { OOIP } & \text { the original oil in place } \\ \text { ORI } & \begin{array}{l}\text { oil recovery index, the ratio of } \\ \text { localised oil produced to average oil }\end{array} \\ & \begin{array}{l}\text { produced } \\ \mathrm{P}_{\mathrm{c}}\end{array} \\ \mathrm{S}_{\mathrm{oi}} & \text { capillary pressure } \\ \mathrm{S}_{\mathrm{or}} & \text { residual (remaining) oil saturation } \\ \mathrm{S}_{\mathrm{wi}} & \text { initial (irreducible) water saturation } \\ \phi & \text { porosity }\end{array}$

\section{Acknowledgements}

The authors would like to thank their colleagues in the Reservoir Description Group for their help and support. We also thank Martin Connell of Royal Infirmary of Edinburgh for developing the software on the used for imaging analysis. This work is part of the Reservoir Heterogeneity Project, funded by Amerada Hess, Bow Valley, British Gas, Chevron, Conoco, Deminex, Elf, Esso, Mobil, Shell, and the UK Department of Trade and Industry.

\section{References}

1. Corbett, P. W. M., Ringrose, P. S., Jensen, J.L., and Sorbie, K. S.: "Laminated clastic reservoirs - the interplay of capillary pressure and sedimentary architecture." Paper SPE 24699 presented at the SPE Annual Technical Conference, Washington, October 4-7, 1992.

2. Ringrose, P. S., Sorbie, K. S., Corbett, P. W. M. and Jensen, J. L.:"Immiscible Flow Behaviour in Laminated and Cross-Bedded Sandstones", Journal of Petroleum Science and Engineering (1993), 9, 103-124.

3. Huang, Y., Ringrose, P.S., Sorbie, K.S., and Tudhope, S.W.: "Waterflood Displacement Mechanisms in a Laminated Rock Slab: Validation of Predicted Capillary Trapping Mechanisms", Paper SPE 28942, presented at SPE Annual Tech. Conf. and Exhib., New Orleans, LA, Sept. 1994.

4. Huang, Y., Ringrose, P.S., Sorbie, K.S.,: "X-ray Imaging of Waterflood Fluid Saturations in Heterogeneous Rock Slabs", Paper SPE 30000, presented at SPE Beijing Meeting, Beijing, China, Nov. 1995.

5. Ringrose, P.S., Sorbie, K.S., Feghi, F., Pickup, G.E. and Jensen, J. L.: "Relevant Reservoir Characterisation: Recovery Process, Geometry and Scale", In Situ (1993), 17(1), 55-82.

6. McDougall, S. R. and Sorbie, K. S.: "The combined 
effect of capillary and viscous forces on waterflood displacement efficiency in finely laminated porous media. Paper SPE 26659, presented at the Annual Technical Conference and Exhibition, Houston, Texas, 3-6th October, 1993.

7. Kortekaas, T. F. M.: "Water/oil displace- ment characteristics in cross-bedded reservoir zones. Society of Petroleum Engineers' Journal (1985) . 25(6): 917-926.

8. Hornarpour, M. M., Cullick, A. S. and Saad, N., "Influence of Small-Scale Rock Laminations on Core Plug Oil-Water Relative Permeability and Capillary Pressure", SPE 27968, University of Tulsa Centenial, Aug. 29-31, 1994, Tulsa, OK.

9. Saad, N., Cullick, A. S. and Hornarpour, M. M., "Effective relative permeability in scale-up and simulation. SPE 29592, Joint Rocky Mountain Regional Mtg and Low-Permeability Reservoirs Symposium, 20-22 Mar., 1995, Denver, CO.
10. Jones, A., Doyle, J., Jacobsen, T., and Kjønsvik, D.: Which Sub-seismic heterogeneities influence waterflood performance? A case study of a low net-to-gross fluvial reservoir. Proc. of the 7th European IOR Symposium, Moscow, Russia, $27-$ 29 October, 1993.

11. Kocberber, S. and Collins, R. E.:"Impact of Reservoir Heterogeneity on Initial distributions of Hydrocarbons", SPE 20547, 65th SPE Annual Tech. Conf. and Exhib., New Orleans, LA, Sept. 1990.

12. Yortsos, Y. C. and Chang, J., "Capillary Effects in Steady-sate Flow in Heterogeneous Cores", Trans. in Porous Media (1990), 5, 399-420.

13. Chang, J. and Yortsos, Y. C., "Effect of Capillary Heterogeneity on Buckley-Leverett Displacement" SPE Reservoir Engineering, pp. 285-294, May 1992.

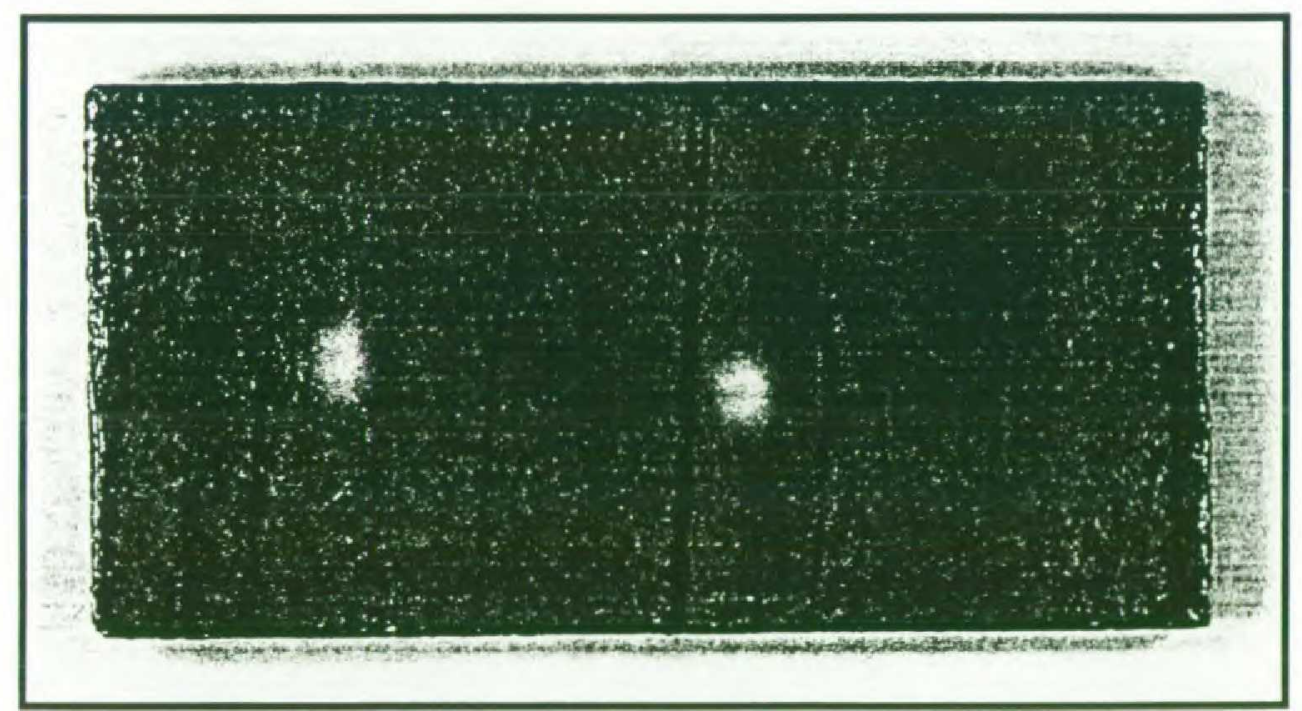

a. Slab C3 (with laminations across the slab)

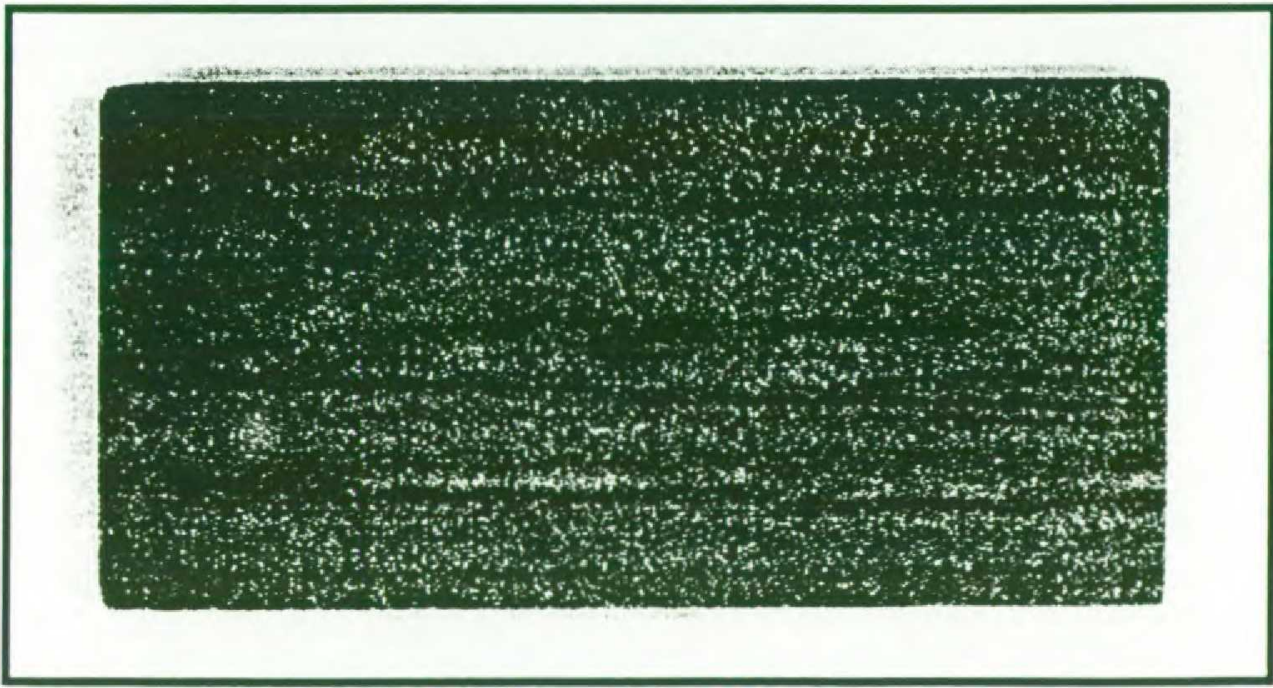

b. Slab P5 (with laminations along slab)

Figure 1. Photographs of rock slabs 


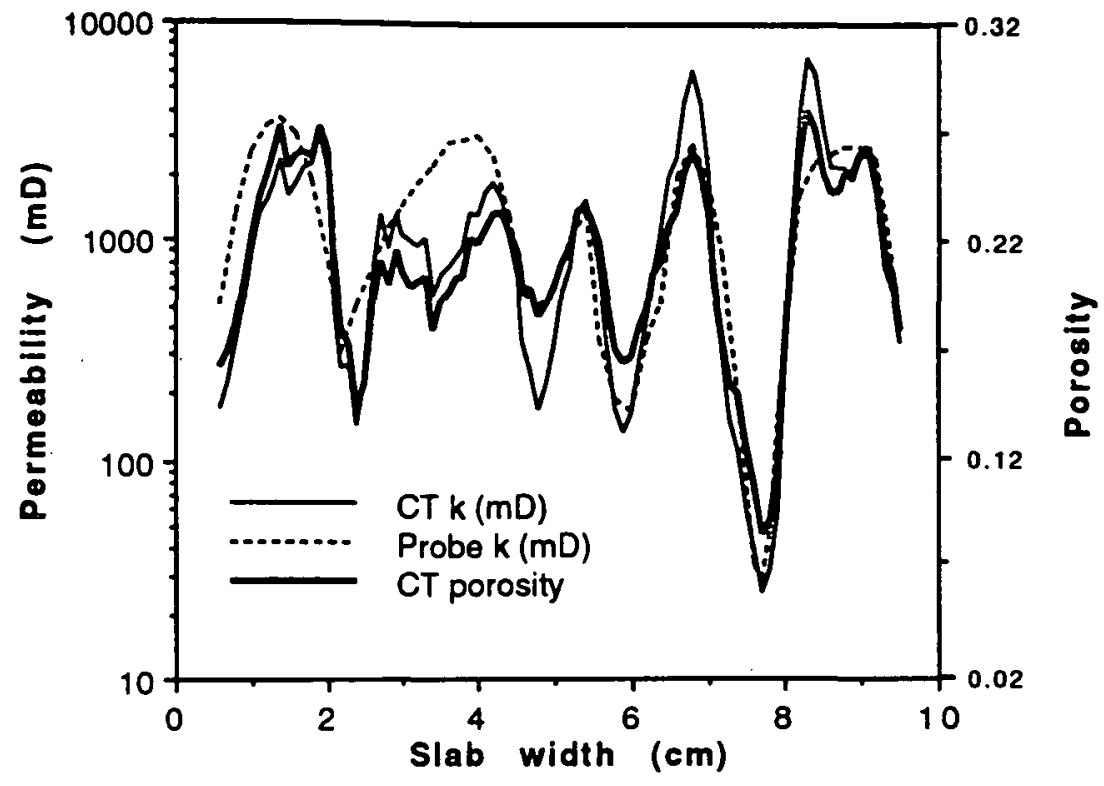

Figure 2 Porosity and permeability distributions in slab P5

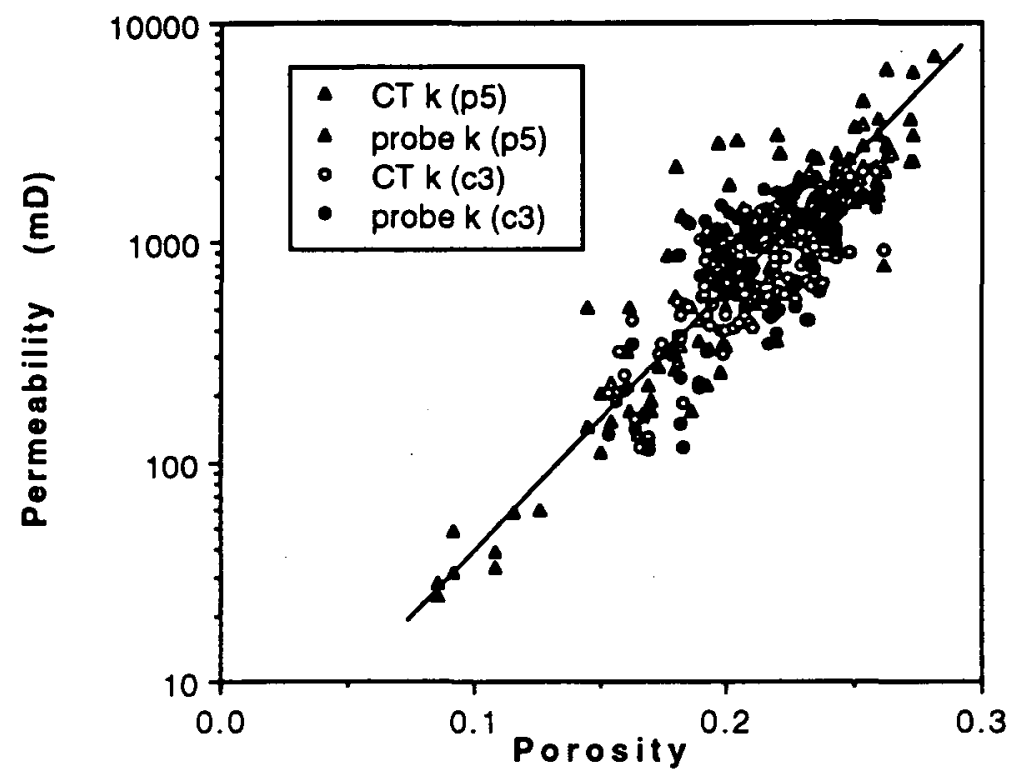

Figure 3 Plots of permeability as a function of porosity

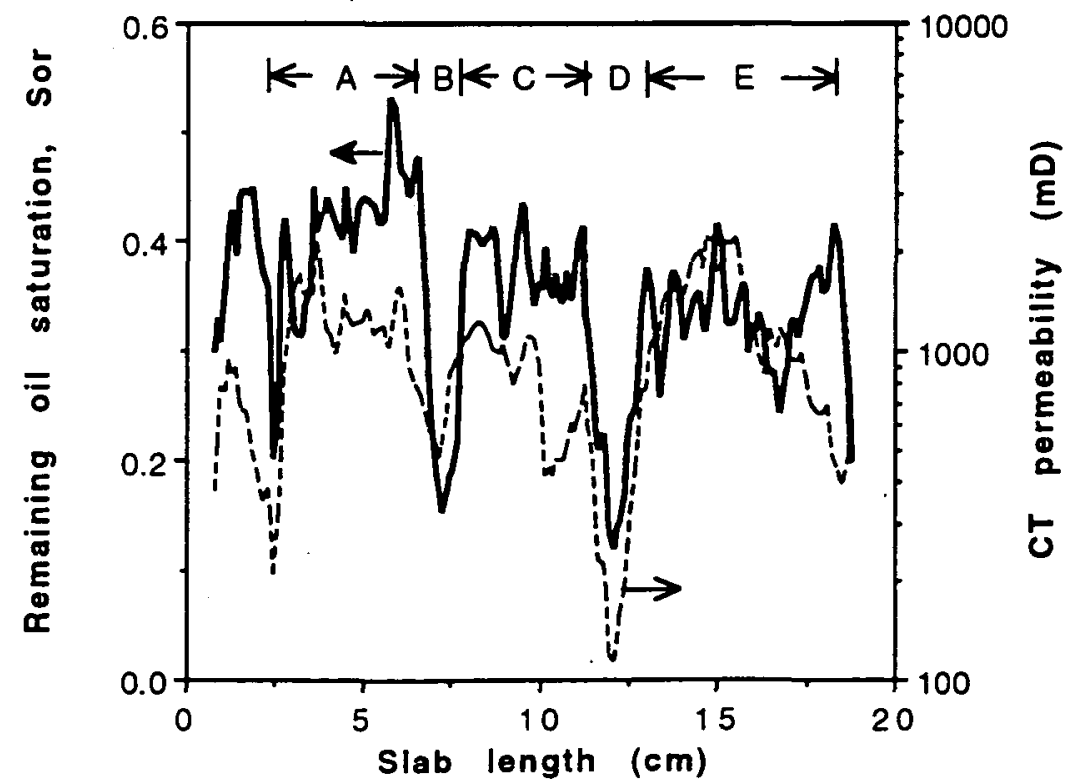

Figure 4 Distribution of remaining oil saturation, Sor, for experiment C3B (cross-lamina injection) 


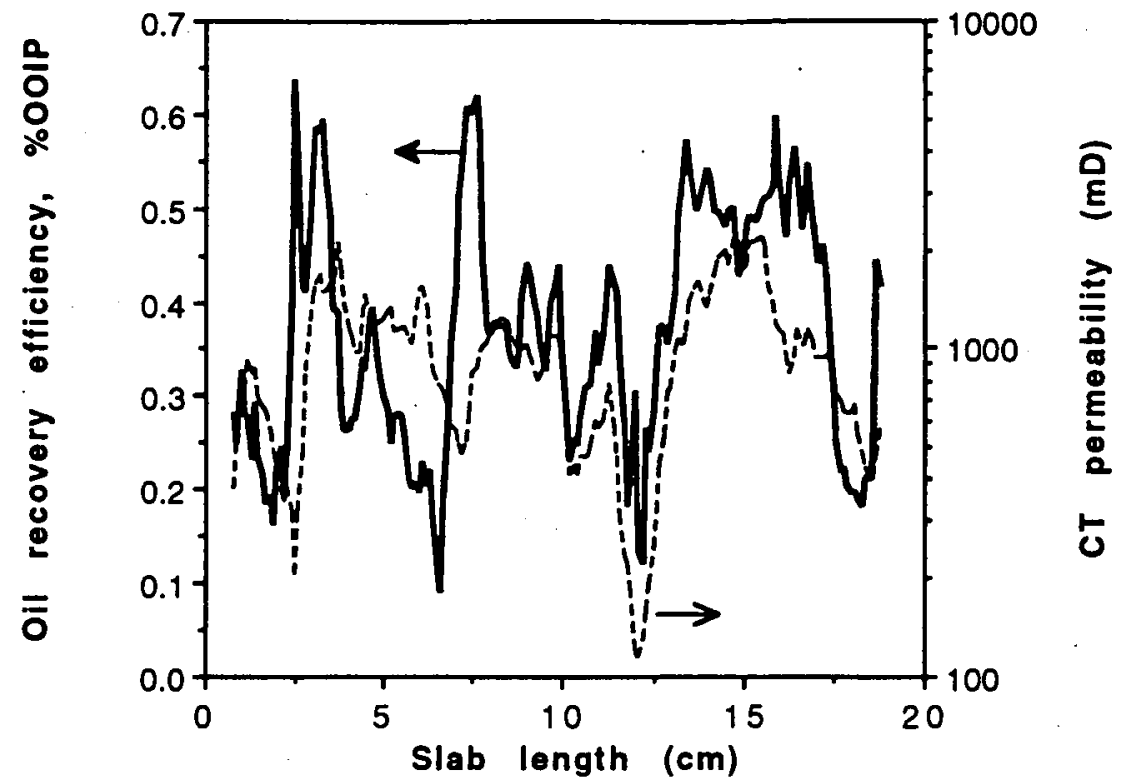

Figure 5 Distribution of oil recovery efficiency, \%OOIP, for experiment C3B (cross-lamina injection)

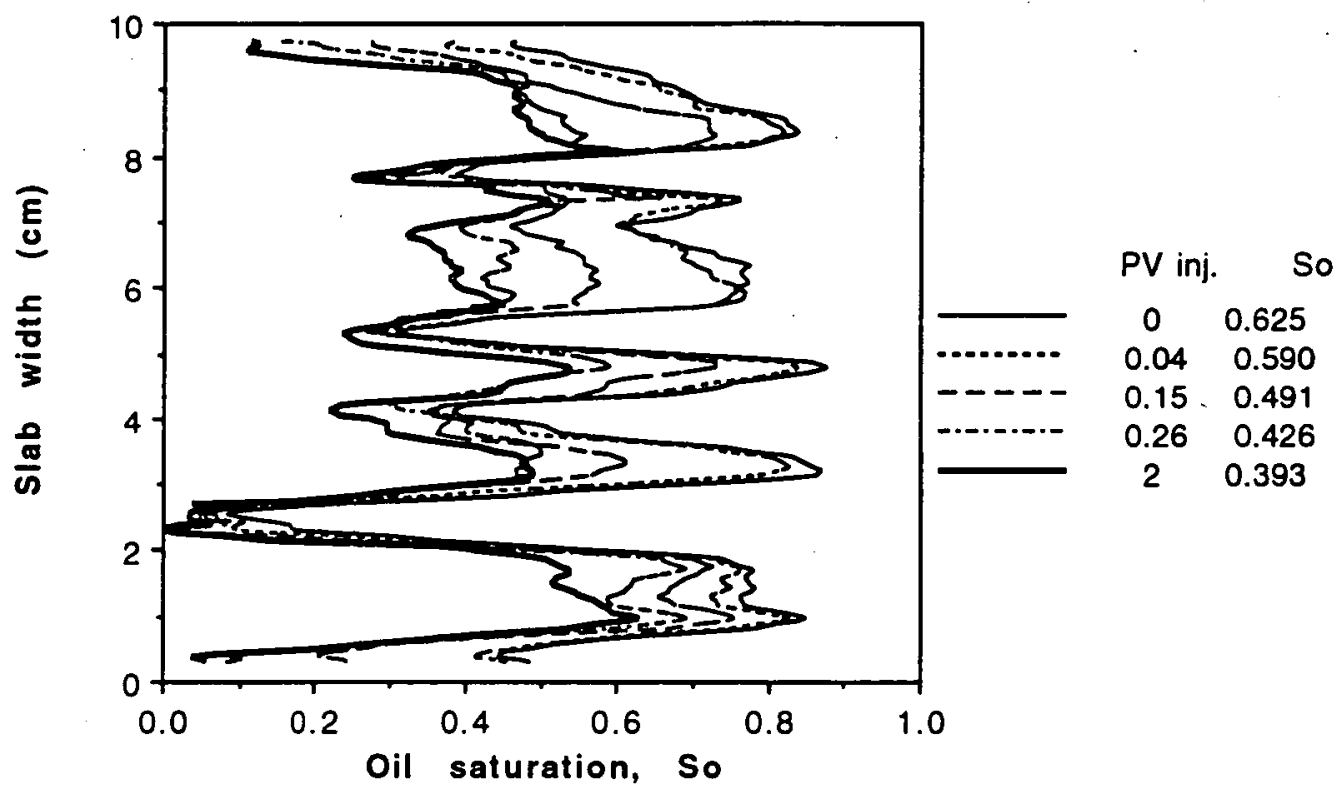

Figure 6 The distribution of oil saturation during brine postflush for experiment P5B (along-lamina injection)

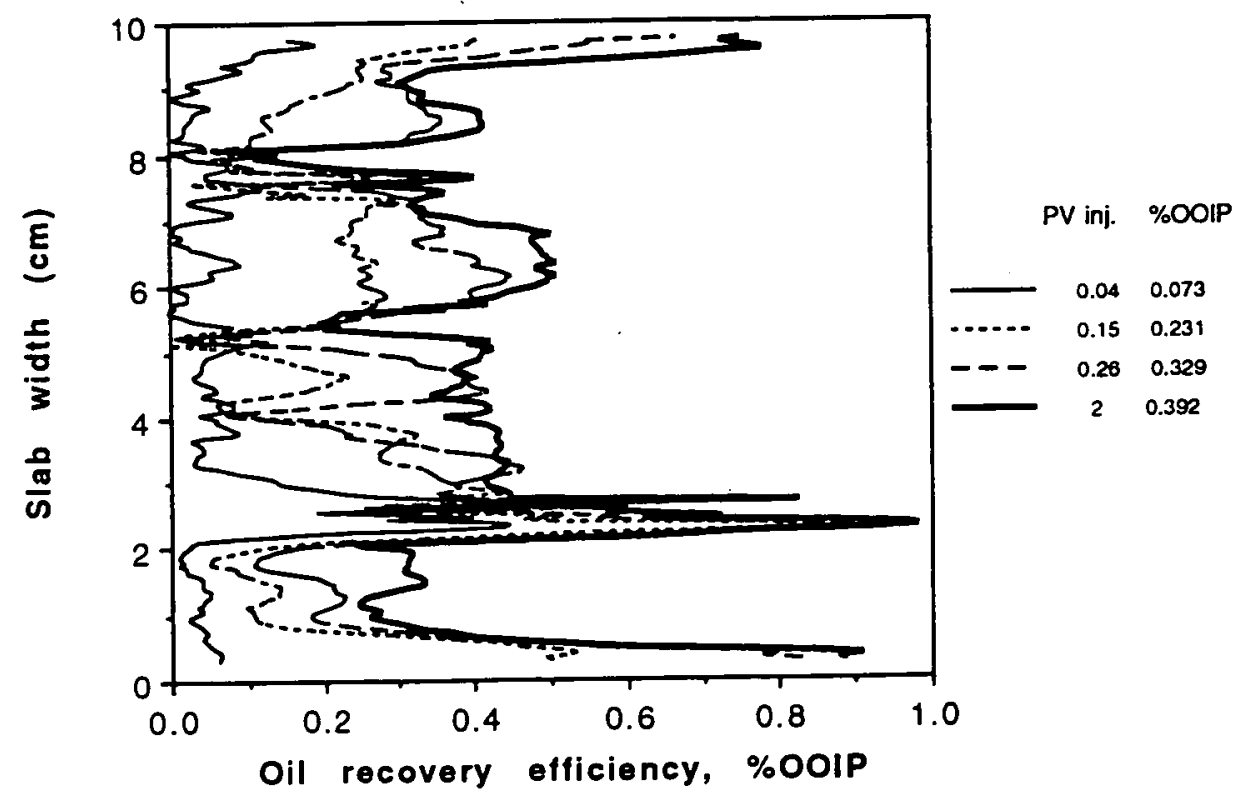

Figure 7 The oil recovery distribution during brine postflush for experiment P5B (along-lamina injection) 


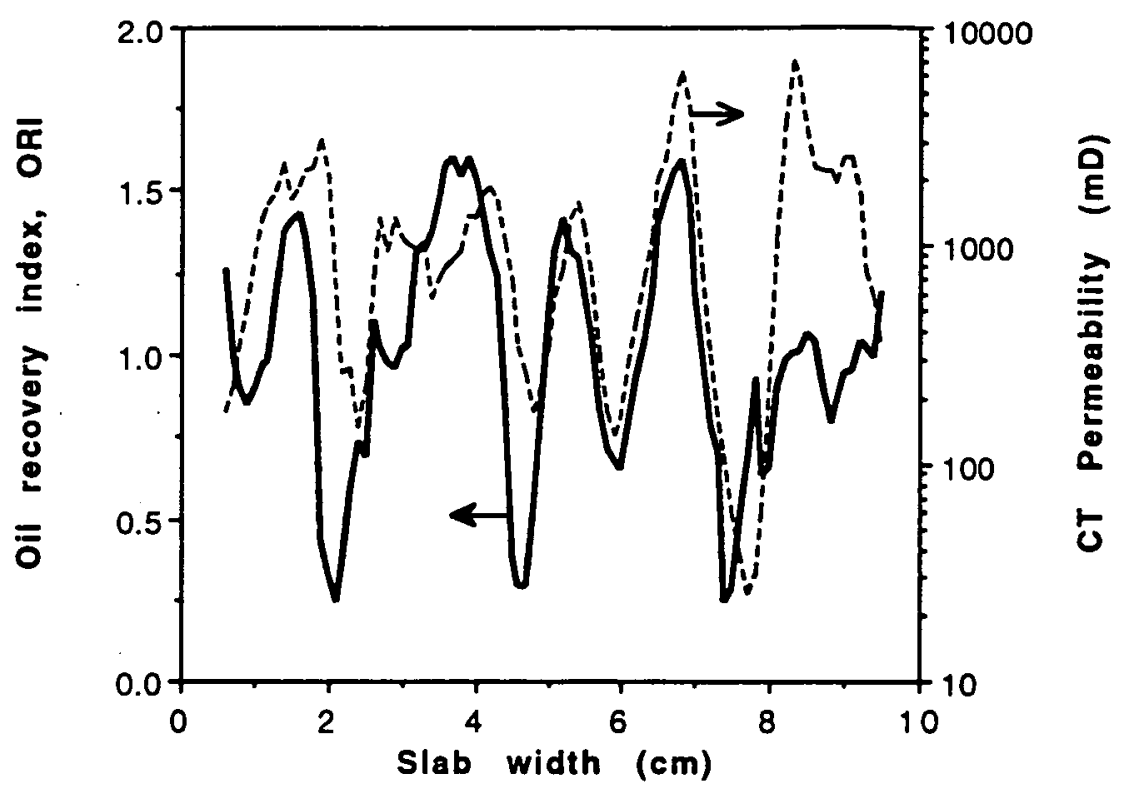

Figure 8 A comparison of profiles of oil recovery index with permeability for experiment P5B (along-lamina injection)

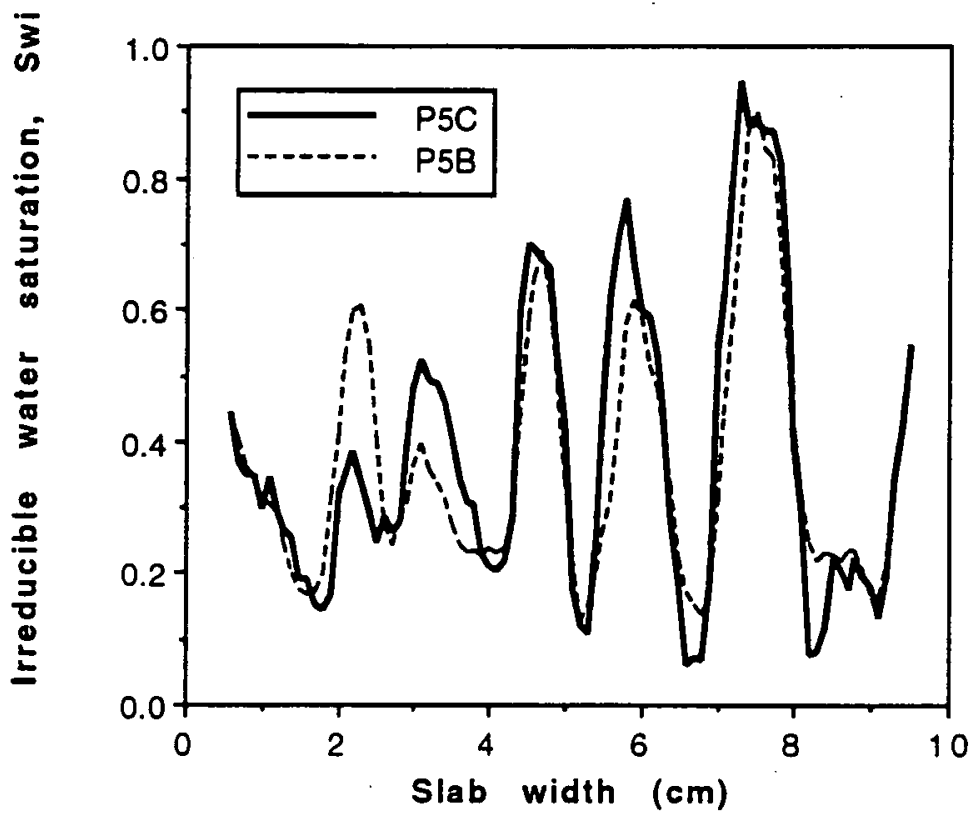

Figure 9 A comparison of the distribution of irreducible water saturation, Swi, for experiment P5B and P5C

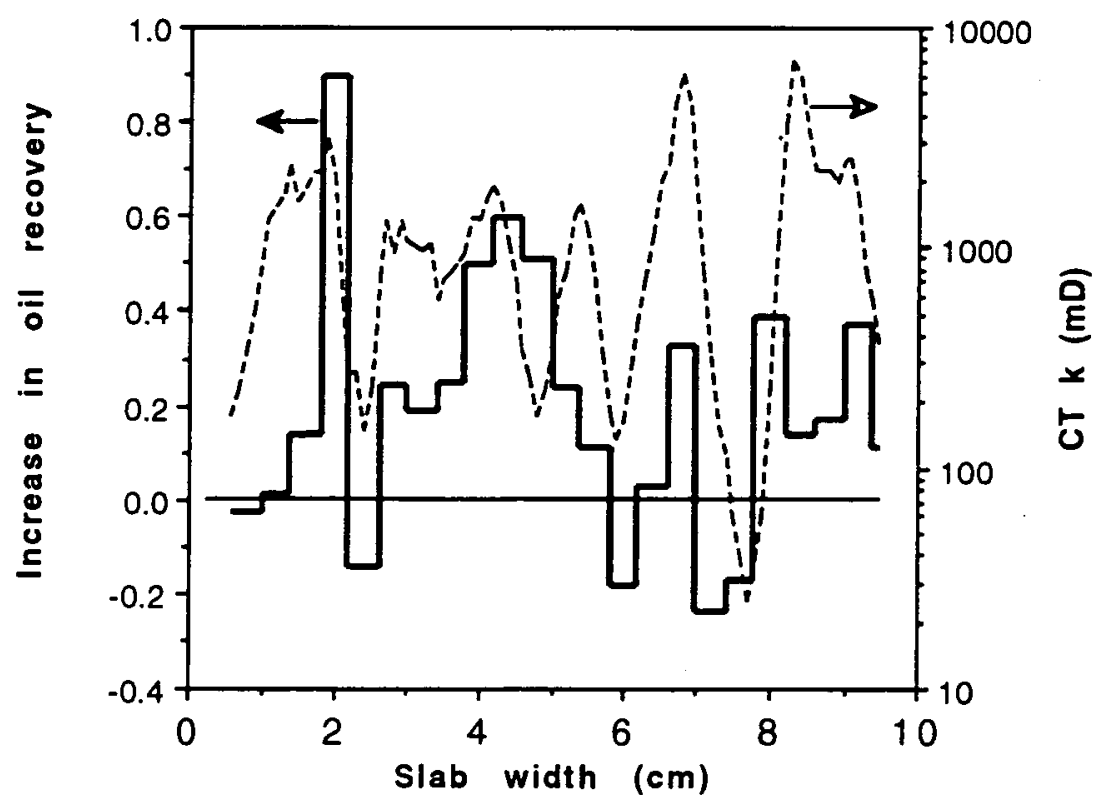

Figure 10 Increase in oil recovery (average 20\%) at the high-rate flood (P5C) compared with at the low-rate flood (P5B) (along-lamina injection) 